Bulletin of Pharmaceutical Sciences
Assiut University
Website: http://bpsa.journals.ekb.eg/
e-mail: bullpharm@aun.edu.eg

\title{
INFLUENCE OF DIFFERENT RESTORATIVE MATERIALS ON THE SENSITIVITY OF STREPTOCOCCUS MUTANS BIOFILM TO DIFFERENT ANTIMICROBIAL MOUTHRINSES IN-VITRO
}

\author{
Al-Agha Nermin ${ }^{1 *}$, Al-Ammori Mostafa ${ }^{1}$ and Koushaji Chaza ${ }^{2}$ \\ ${ }^{1}$ Department of Biochemistry and Microbiology, Faculty of Pharmacy, Damascus University, \\ Damascus, Syria \\ ${ }^{2}$ Professor in Pediatric Dentistry, Faculty of Dentistry, Damascus University, Damascus, Syria
}

\begin{abstract}
Objectives: The aim of this study was to assess the antibacterial effects of chlorhexidine gluconate, sodium fluoride, and sodium fluoride-xylitol combination mouthrinses on S. mutans biofilm in-vitro, and most significantly, we aimed to compare different restorative materials regarding the sensitivity of $S$. mutans biofilms formed on their surfaces to the antibacterial effects of the tested mouthrinses. Results: Chlorhexidine gluconate $0.12 \%$, sodium fluoride $0.05 \%$, and sodium fluoride $0.05 \%$ - xylitol $25 \%$ combination exhibited statistically significant antibacterial effects on S. mutans biofilm. The addition of xylitol $25 \%$ to sodium fluoride $0.05 \%$ mouthrinse was associated with higher antibacterial effects compared with sodium fluoride alone. S. mutans biofilms formed on GIC specimens exhibited the highest sensitivity to antibacterial treatments, whereas biofilms formed on stainless steel specimens showed the lowest sensitivity. Conclusion: S. mutans biofilms formed on different restorative materials exhibited different sensitivity levels to antimicrobial mouthrinses.
\end{abstract}

\section{INTRODUCTION}

Restorative care involves restoration of carious teeth with dental materials such as amalgams, composite resins, or glass inomercements. However, in the case of large multisurface carious lesions, stainless steel crowns are usually used ${ }^{1}$. Despite the huge advantages associated with restorative treatment, these materials still have some drawbacks; mainly secondary caries vulnerability ${ }^{2}$.

The adhesion of oral bacteria, especially Streptococcus mutans (S. mutans), to teeth and restorative materials and the consequent biofilm formation on these surfaces is the main cause of plaque related diseases and restorative treatment failure ${ }^{3}$. While primary caries cases are responsible for less than half of the dental restorations produced annually, most of the restorations are applied for the replacement of old restorations, and the majority of these require replacement because of secondary caries ${ }^{1}$. In-vivo and in-vitro studies have demonstrated that $S$. mutans is strongly associated with caries development as it's often isolated from plaque samples of either natural or restorative surfaces during early stages of caries $^{4}$.

Several conventional restorative materials have been proposed to have antibacterial and anti-biofilm properties, such as amalgams and glass inomer cements, mainly due to the release of metallic ions and fluoride respectively. On the other hand, composite resins were found to lack any antimicrobial effect; in fact these fillings were shown to promote bacterial growth and biofilm formation, especially for $S$. mutans 5 .

One of the convenient approaches for reducing biofilm formation on the surfaces of natural teeth and restorative materials is the use of antimicrobial mouthrinses ${ }^{3}$. Various 
antimicrobial agents may appear to be convenient for plaque control. However, only few were found to be clinically efficient. That's because many antimicrobial agents lack substantivity and efficacy against oral bacteria ${ }^{6}$.

Chlorhexidine is a bisbiguanide compound with cationic properties. It has a wide spectrum including most of the Gram positive and Gram negative bacteria, bacterial spores, lipophilic viruses, as well as yeasts etc. Several studies have reported the ability of chlorhexidine to suppress $S$. mutans count in saliva and dental plaque, thus limiting the incidence of dental caries $^{7}$. Chlorhexidine is considered the golden standard against which the efficacies of other antimicrobial agents are compared. However, the use of chlorhexidine is associated with a common side effect; which is brownish staining of teeth, as well as restorations, and tongue ${ }^{7}$.

Various studies have stated that fluoride decreases the occurrence of dental caries and slows down or even reverses the progression of existing lesions mainly by reducing the rate of enamel demineralization and increasing the rate of re-mineralization. Fluoride can also influence bacterial metabolism directly. However, the significance of this mechanism is still disputed ${ }^{8}$.

Xylitol is a naturally occurring five-carbon sugar polyol that has been permitted by several countries to be used in foods, pharmaceuticals, and oral health products, mainly in chewing gums, toothpastes, and mouthwashes ${ }^{9}$. The anti caries effect of xylitol has been claimed to be based on the reduction of $S$. mutans levels in plaque and saliva by disturbing bacterial energy production processes, thereby leading to "futile energy cycle" and cell death eventually ${ }^{10}$.

In this in-vitro experimental study, we aimed to assess the antibacterial effects of chlorhexidine gluconate, sodium fluoride, and sodium fluoride-xylitol combination mouthrinses on $S$. mutans biofilm, and most importantly, we aimed to compare different restorative materials regarding the sensitivity of $S$. mutans biofilms formed on their surfaces to the antibacterial effects of the tested mouthrinses.

\section{MATERIALS AND METHODS}

\section{Bacterial Samples Collection}

Samples were collected from children visiting the pediatric clinic in the faculty of dentistry in Damascus University. Sterile cotton swabs were used to collect samples. Afterwards, the swabs were immediately immersed in nutrient broth and incubated for $24 \mathrm{hrs}$ at $37^{\circ} \mathrm{C}$.

\section{Isolation and identification of Streptococcus mutans}

Each sample was streaked on Mitis Salivarius Agar plate (HiMedia, India) and incubated in a microaerophilic environment using candle jar method for $48 \mathrm{hrs}$ at $37^{\circ} \mathrm{C}$. Morphologically different colonies were regrown separately on Mitis Salivarius Agar for another $48 \mathrm{hrs}$ (candle jar, $37^{\circ} \mathrm{C}$ ) in order to obtain pure cultures. Gram stain and biochemical tests (mannitol fermentation, sorbitol fermentation, arginine hydrolysis, and $\mathrm{NaCl} 6.5 \%$ tolerance) were used to identify Streptococcus mutans isolates. All of the biochemical tests were carried out manually using phenol red broth (Liofilchem, Italy) for mannitol and sorbitol fermentation tests, nutrient broth (Abtek, UK) $+6.5 \% \mathrm{NaCl}$ for $\mathrm{NaCl} 6.5 \%$ tolerance test. Todd Hewitt broth (Abtek, UK) and Moeller's decarboxylase broth (Abtek, UK) were used for arginine hydrolysis test. The scheme of the biochemical reactions used to identify $S$. mutans is elucidated in figure 1 . Ten clinical isolates were identified and preserved at $+4^{\circ} \mathrm{C}$ on Tryptic Soya Agar slants (TSA, HiMedia, India) and periodically transferred to fresh media.

\section{Enamel and Dental restorative specimens' preparation}

In this in-vitro experimental study, specimens of four commercial dental restorative materials (resin composite, glassinomer cement, amalgam, and stainless steel crowns) in addition to enamel as a control were tested. Table 1 shows the tested materials. Disks were fabricated with $5 \mathrm{~mm}$ diameter and $2 \mathrm{~mm}$ thickness as follows: First, Enamel specimens were carved out of intact premolars with no caries, or restorations, which had been extracted due to orthodontic treatment plans. 
Table 1: Restorative materials used in this study.

\begin{tabular}{|l|l|}
\hline \multicolumn{1}{|c|}{ Restorative material } & \multicolumn{1}{c|}{ Material type } \\
\hline${\text { EcoSphere shape }\left(\mathrm{DMG}^{\circledR}\right)}^{\circledR}$ & Resin composite \\
\hline Medicem $\left(\right.$ PROMEDICA $\left.^{\circledR}\right)$ & Glass-inomer cement \\
\hline Non gamma 2 alloy $\left(\mathrm{BMS} \mathrm{DENTAL}^{\circledR}\right)$ & Amalgam \\
\hline Kids crown ${ }^{\circledR}$ & Stainless steel crown \\
\hline
\end{tabular}

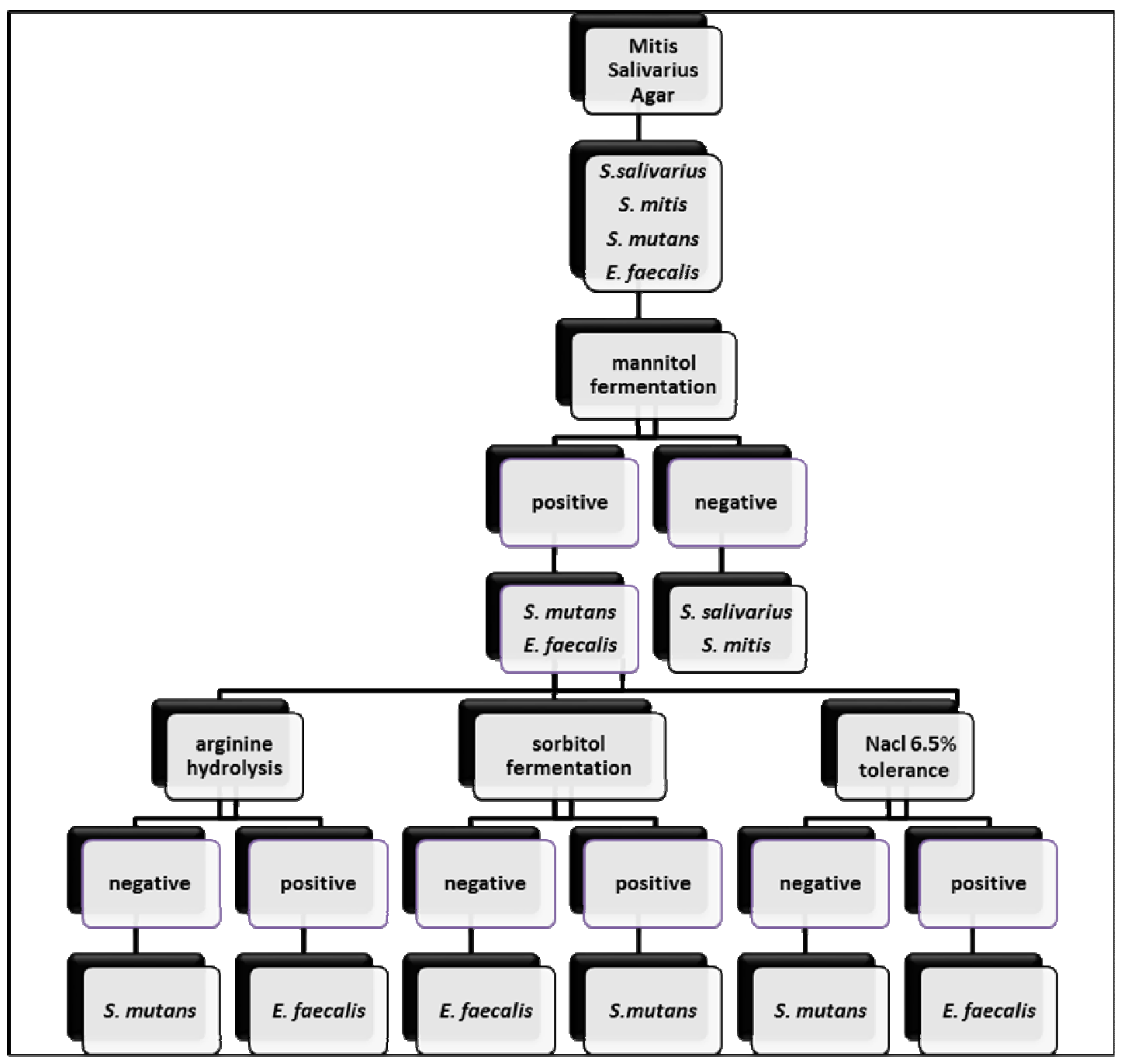

Fig. 1: The scheme of the biochemical reactions used to identify S. mutans.

Then, enamel blocks were used to form identical holes with the above mentioned dimensions in a rubber silicon mold. The silicon mold was used to produce disk shaped specimens of amalgam, GIC, and resin composite according to manufacturer's instructions for each material. Resin composite specimens were light cured for 40 seconds on each side and all of the disks were finished following the clinically recommended methods. Stainless steel specimens were carved out of prefabricated stainless steel crowns corresponding to the same surface area of the disks $\left(70.65 \mathrm{~mm}^{2}\right)$. All specimens were sterilized by autoclaving for $15 \mathrm{~min}$ at $121^{\circ} \mathrm{C}^{11 \& 12}$. 


\section{Saliva Coating of the Specimens}

Unstimulated saliva from one healthy donor was collected over the period of several days. Subsequently, the saliva samples were pooled and centrifuged $\left(30 \mathrm{~min} ; 4^{\circ} \mathrm{C} ; 2500\right.$ $\mathrm{rpm})$. The supernatant was transported into new sterile tubes and heated in a water bath $\left(60^{\circ} \mathrm{C}, 30 \mathrm{~min}\right)$, re-centrifuged $\left(30 \mathrm{~min}, 4^{\circ} \mathrm{C}\right.$; $2500 \mathrm{rpm}$ ), and stored at $-20^{\circ} \mathrm{C}^{13} \cdot 100 \mu \mathrm{L}$ of saliva was plated onto nutrient agar and incubated for $48 \mathrm{hrs}$, no bacterial growth was observed indicating the elimination of bacteria that could disturb the biofilm formation test. The sterile disks were placed in sterile eppendorf tubes containing $100 \mu \mathrm{L}$ of saliva for $2 \mathrm{hrs}$ to allow salivary pellicle formation ${ }^{14}$.

\section{Biofilm formation assay}

A bacterial suspension was prepared from each of the ten clinical isolates of $S$. mutans by harvesting the colonies from nutrient agar plates previously inoculated and incubated aerobically for $24 \mathrm{hrs}$ at $37^{\circ} \mathrm{C}$. Subsequently, these colonies were suspended in sterile saline. The turbidity of the bacterial suspension was adjusted to 0.5 Mcfarland $\left(1.5 \times 10^{8} \mathrm{CFU} / \mathrm{ml}=\right.$ $\left.1.5 \times 10^{7} \mathrm{CFU} / 100 \mu \mathrm{l}\right)$.

After the formation of the salivary pellicle, the specimens were transported to new eppendorf tubes containing $100 \mu \mathrm{l}$ of the bacterial suspension and incubated for $24 \mathrm{hrs}$ at $37^{\circ} \mathrm{C}$ to allow the formation of $S$. mutans biofilm on the surface of the specimens. Afterwards, the specimens were gently rinsed with sterile saline to remove unattached cells; subsequently the specimens were vortexed in sterile tubes containing $1.5 \mathrm{ml}$ of sterile saline for two minutes ${ }^{15}$. Serial dilutions were made from each of these tubes and $0.1 \mathrm{ml}$ of each dilution was cultured on the surface of nutrient agar and incubated at $37^{\circ} \mathrm{C}$ for $24 \mathrm{hrs}$. Afterwards, colonies were counted by unaided vision and the number of $S$. mutans cells adhered on the surface of the restorative materials was expressed in $\mathrm{CFU} / \mathrm{ml}$ and then converted to CFU/mm $\mathrm{mm}^{2}$ (adherent cells on the specimens).

\section{Evaluation of the anti-biofilm activity}

First, biofilms of $S$. mutans isolates were formed on the surface of the specimens following the same procedures carried out previously. After biofilm formation, and rinsing of the specimens to remove unattached cells, these specimens were transferred into new tubes containing $100 \mu 1$ of one of the three tested mouthrinses, and were set for 1 minute. Afterwards, the specimens were rinsed gently with sterile saline to remove the traces of the antibacterial mouthrinse. The specimens were then vortexed in sterile tubes containing $1.5 \mathrm{ml}$ of sterile saline for two minutes ${ }^{16 \& 17}$. Serial dilutions were made from each of these tubes and $0.1 \mathrm{ml}$ of each dilution was cultured on the surface of nutrient agar and incubated at $37^{\circ} \mathrm{C}$ for $24 \mathrm{hrs}$. Colonies were then counted by unaided vision and the number of $S$. mutans cells still adhered on the surface of the specimens after the application of the antibacterial treatment was expressed in $\mathrm{CFU} / \mathrm{ml}$ then converted to $\mathrm{CFU} / \mathrm{mm}^{2}$ and compared with the base level of adhesion before the application of the mouthrinses.

\section{Statistical Analysis}

All experiments were conducted twice; Wilcoxon test was used to assess the effectiveness of the tested mouthrinses on $S$. mutans biofilms, and paired sample t-test was used to compare the tested restorative materials regarding the sensitivity of $S$. mutans biofilms formed on their surfaces to the antimicrobial treatments. The significance level was set at 0.05 .

\section{RESULTS AND DISCUSSION}

\section{Results}

Table 2 and figure 2 show the numbers of $S$. mutans cells adhered to the surface of each of the restorative materials before the application of any antimicrobial treatment, and after the application of chlorhexidine gluconate $0.12 \%$, sodium fluoride $0.05 \%$, and sodium fluoride $0.05 \%$ - xylitol $25 \%$ combination respectively.

All of the three antibacterial mouthrinses tested significantly reduced the count of $S$. mutans in the biofilms formed on the surfaces of all of the tested restorative materials $(p<0.05)$.

Table 3 shows the mean decrease in the number of S. mutans in the biofilms formed on the surfaces of the tested restorative materials after the application of the tested antibacterial mouthrinses on these materials. Comparing 
Table 2: Number $\left(\log _{10} . \mathrm{CFU} / \mathrm{mm}^{2}\right)$ of $S$. mutans cells adhered to the surface of the tested restorative materials.

\begin{tabular}{|c|c|c|c|c|c|c|}
\hline \multicolumn{2}{|c|}{ Clinical isolate } & \multirow{2}{*}{$\begin{array}{c}\begin{array}{c}\text { Stainless } \\
\text { steel }\end{array} \\
3 \\
\end{array}$} & \multirow{2}{*}{$\begin{array}{c}\text { Amlagam } \\
3.6 \\
\end{array}$} & \multirow{2}{*}{$\begin{array}{c}\text { GIC } \\
4.6 \\
\end{array}$} & \multirow{2}{*}{$\begin{array}{c}\begin{array}{c}\text { Composite } \\
\text { resin }\end{array} \\
5\end{array}$} & \multirow{2}{*}{$\begin{array}{c}\text { Ename } \\
4.6 \\
\end{array}$} \\
\hline \multirow{4}{*}{$\mathrm{S} 1$} & Base level of adhesion & & & & & \\
\hline & $\begin{array}{c}\text { After application of CHX } \\
0.12 \% \\
\end{array}$ & 0.9 & 1 & 1.3 & 3.3 & 1.6 \\
\hline & $\begin{array}{c}\text { After application of } \mathrm{NaF} \\
0.05 \%\end{array}$ & 2.7 & 1.7 & 2.6 & 3.6 & 2.6 \\
\hline & $\begin{array}{c}\text { After application of } \mathrm{NaF} \\
0.05 \%+\text { xylitol } 25 \%\end{array}$ & 2.6 & 1 & 1 & 3 & 2.6 \\
\hline \multirow{4}{*}{$\mathrm{S} 2$} & Base level of adhesion & 1.3 & 3 & 3.7 & 4 & 4 \\
\hline & $\begin{array}{c}\text { After application of } \mathrm{CHX} \\
0.12 \%\end{array}$ & 0 & 0 & 0 & 1 & 1.3 \\
\hline & $\begin{array}{c}\text { After application of } \mathrm{NaF} \\
0.05 \% \\
\end{array}$ & 1.3 & 2.6 & 2.3 & 2.7 & 3 \\
\hline & $\begin{array}{c}\text { After application of } \mathrm{NaF} \\
0.05 \%+\text { xylitol } 25 \%\end{array}$ & 1.3 & 2 & 1.9 & 2.7 & 2.7 \\
\hline \multirow{4}{*}{ S3 } & Base level of adhesion & 2.3 & 3.3 & 4 & 4 & 4 \\
\hline & $\begin{array}{c}\text { After application of CHX } \\
0.12 \%\end{array}$ & 1.3 & 0.3 & 1.6 & 3 & 2.6 \\
\hline & $\begin{array}{c}\text { After application of } \mathrm{NaF} \\
0.05 \%\end{array}$ & 1.3 & 2.7 & 1.3 & 2.3 & 3.6 \\
\hline & $\begin{array}{c}\text { After application of } \mathrm{NaF} \\
0.05 \%+\text { xylitol } 25 \%\end{array}$ & 1.3 & 1.6 & 1.3 & 2.3 & 2.6 \\
\hline \multirow{4}{*}{ S4 } & Base level of adhesion & 1.6 & 3.3 & 3.9 & 3.9 & 4 \\
\hline & $\begin{array}{c}\text { After application of CHX } \\
0.12 \%\end{array}$ & 0.9 & 0 & 0 & 1.6 & 1.6 \\
\hline & $\begin{array}{c}\text { After application of } \mathrm{NaF} \\
0.05 \%\end{array}$ & 1.3 & 2 & 2.6 & 3.6 & 2.6 \\
\hline & $\begin{array}{c}\text { After application of } \mathrm{NaF} \\
0.05 \%+\text { xylitol } 25 \%\end{array}$ & 1.3 & 1.3 & 1.3 & 2 & 2.3 \\
\hline \multirow{4}{*}{ S5 } & Base level of adhesion & 1.6 & 2.7 & 3.6 & 3.7 & 4.3 \\
\hline & $\begin{array}{c}\text { After application of CHX } \\
0.12 \%\end{array}$ & 0.9 & 0 & 1.3 & 0.7 & 1 \\
\hline & $\begin{array}{c}\text { After application of } \mathrm{NaF} \\
0.05 \%\end{array}$ & 1.6 & 1.6 & 2.6 & 2.6 & 2.6 \\
\hline & $\begin{array}{c}\text { After application of } \mathrm{NaF} \\
0.05 \%+\text { xylitol } 25 \%\end{array}$ & 1.6 & 1 & 1.3 & 2.6 & 2.6 \\
\hline \multirow{4}{*}{ S6 } & Base level of adhesion & 2.7 & 3.6 & 4.7 & 4.9 & 4.6 \\
\hline & $\begin{array}{c}\text { After application of CHX } \\
0.12 \% \\
\end{array}$ & 1.3 & 0 & 0 & 3 & 1.6 \\
\hline & $\begin{array}{c}\text { After application of } \mathrm{NaF} \\
0.05 \%\end{array}$ & 2 & 2.6 & 2 & 3.7 & 2.6 \\
\hline & $\begin{array}{c}\text { After application of } \mathrm{NaF} \\
0.05 \%+\text { xylitol } 25 \%\end{array}$ & 2 & 2.3 & 1 & 3.7 & 2.6 \\
\hline \multirow{4}{*}{ S7 } & Base level of adhesion & 1.6 & 2.7 & 3.3 & 3.7 & 3.6 \\
\hline & $\begin{array}{c}\text { After application of } \mathrm{CHX} \\
0.12 \% \\
\end{array}$ & 1.3 & 0.3 & 0.3 & 2.6 & 1.6 \\
\hline & $\begin{array}{c}\text { After application of } \mathrm{NaF} \\
0.05 \% \\
\end{array}$ & 1.6 & 1 & 2.7 & 3.6 & 3.6 \\
\hline & $\begin{array}{c}\text { After application of } \mathrm{NaF} \\
0.05 \%+\text { xylitol } 25 \%\end{array}$ & 1.6 & 1 & 1.3 & 3.6 & 2.6 \\
\hline
\end{tabular}




\begin{tabular}{|c|c|c|c|c|c|c|}
\hline \multicolumn{2}{|r|}{ Clinical isolate } & $\begin{array}{c}\text { Stainless } \\
\text { steel }\end{array}$ & Amlagam & GIC & $\begin{array}{c}\text { Composite } \\
\text { resin }\end{array}$ & Enamel \\
\hline \multirow{4}{*}{ S8 } & Base level of adhesion & 2.7 & 3.6 & 4.3 & 4.9 & 4.6 \\
\hline & $\begin{array}{c}\text { After application of CHX } \\
0.12 \% \\
\end{array}$ & 1.3 & 0 & 0 & 0.6 & 1.6 \\
\hline & $\begin{array}{c}\text { After application of } \mathrm{NaF} \\
0.05 \%\end{array}$ & 2.7 & 1.6 & 3.7 & 3.7 & 3.7 \\
\hline & $\begin{array}{c}\text { After application of } \mathrm{NaF} \\
0.05 \%+\text { xylitol } 25 \%\end{array}$ & 2.3 & 1.3 & 2.6 & 3.7 & 2.6 \\
\hline \multirow{4}{*}{ S9 } & Base level of adhesion & 2.9 & 3.7 & 4.6 & 4.9 & 4.7 \\
\hline & $\begin{array}{c}\text { After application of CHX } \\
0.12 \%\end{array}$ & 1 & 0 & 0 & 0.6 & 1.3 \\
\hline & $\begin{array}{c}\text { After application of } \mathrm{NaF} \\
0.05 \% \\
\end{array}$ & 2.3 & 2 & 2.6 & 3.6 & 3.6 \\
\hline & $\begin{array}{c}\text { After application of } \mathrm{NaF} \\
0.05 \%+\text { xylitol } 25 \%\end{array}$ & 1.6 & 1.6 & 2.6 & 3.6 & 3.6 \\
\hline \multirow{4}{*}{$\mathrm{S} 10$} & Base level of adhesion & 1.3 & 2.7 & 3.6 & 3.7 & 3.9 \\
\hline & $\begin{array}{c}\text { After application of CHX } \\
0.12 \%\end{array}$ & 0.7 & 0 & 0 & 1.7 & 2.6 \\
\hline & $\begin{array}{c}\text { After application of } \mathrm{NaF} \\
0.05 \%\end{array}$ & 1.3 & 2 & 2.6 & 3.6 & 3.7 \\
\hline & $\begin{array}{c}\text { After application of } \mathrm{NaF} \\
0.05 \%+\text { xylitol } 25 \%\end{array}$ & 1.3 & 2 & 2.6 & 3.6 & 3.6 \\
\hline \multirow{4}{*}{$\begin{array}{c}\text { Aver- } \\
\text { age }\end{array}$} & Base level of adhesion & $2.1 \pm 0.68$ & $3.2 \pm 0.4$ & $4.03 \pm 0.49$ & $4.2 \pm 0.57$ & $4.2 \pm 0.38$ \\
\hline & $\begin{array}{c}\text { After application of CHX } \\
0.12 \%\end{array}$ & $1 \pm 0.40$ & $0.1 \pm 0.32$ & $0.45 \pm 0.66$ & $1.8 \pm 1.08$ & $1.6 \pm 0.52$ \\
\hline & $\begin{array}{c}\text { After application of } \mathrm{NaF} \\
0.05 \% \\
\end{array}$ & $1.81 \pm 0.57$ & $\begin{array}{c}1.98 \pm \\
0.53 \\
\end{array}$ & $2.5 \pm 0.60$ & $3.3 \pm 0.53$ & $3.16 \pm 0.52$ \\
\hline & $\begin{array}{c}\text { After application of } \mathrm{NaF} \\
0.05 \%+\text { xylitol } 25 \%\end{array}$ & $1.72 \pm 0.64$ & $\begin{array}{c}1.51 \pm \\
0.47\end{array}$ & $1.69 \pm 0.67$ & $3.08 \pm 0.64$ & $2.78 \pm 0.44$ \\
\hline
\end{tabular}

$\mathrm{CHX}=$ chlorhexidine gluconate, $\mathrm{NaF}=$ sodium fluoride.

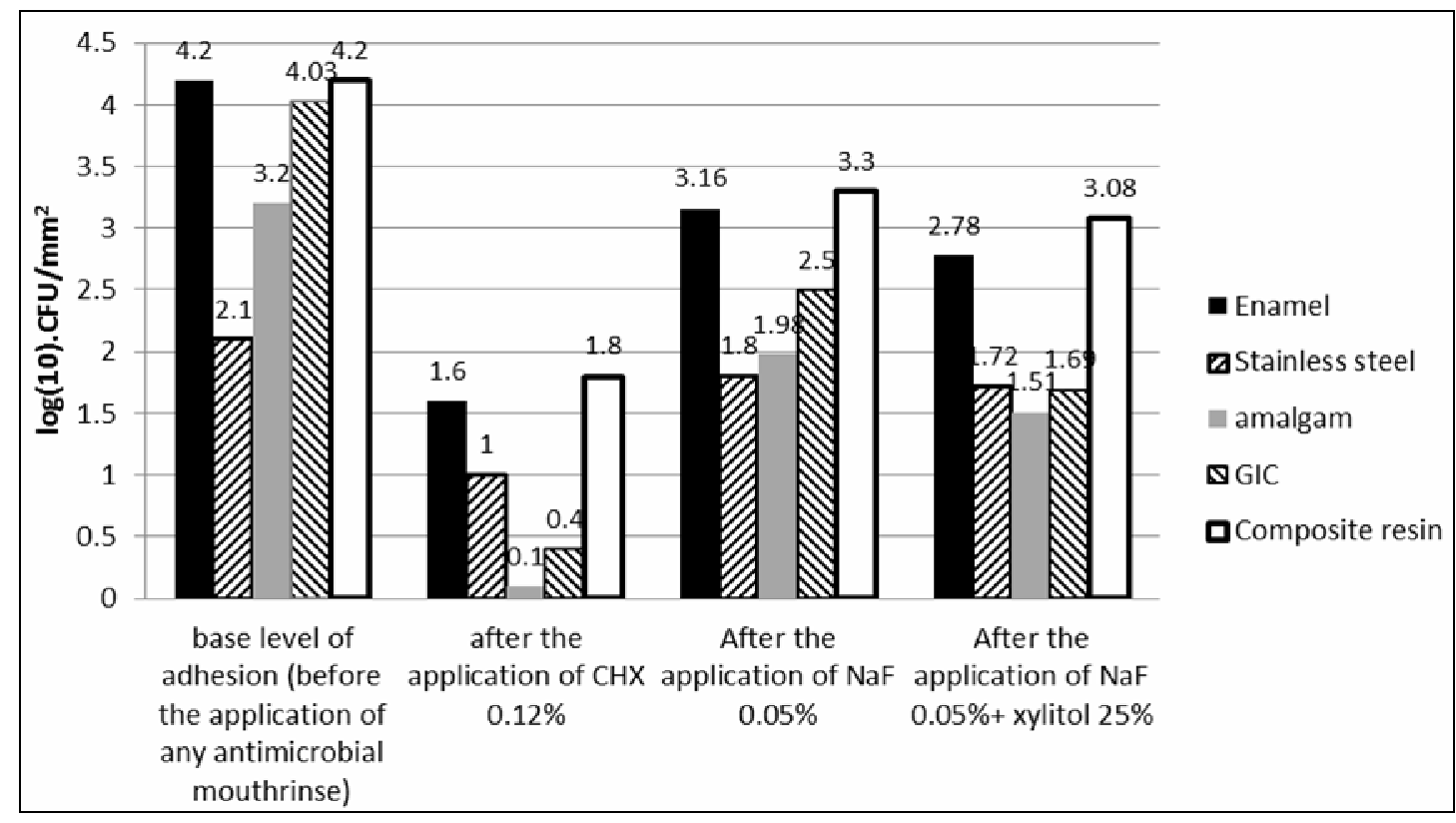

Fig. 2: Number of $S$. mutans cells $\left(\log _{10} . \mathrm{CFU} / \mathrm{mm}^{2}\right)$ adhered onto the surface of tested restorative materials. 
Table 3: The average decrease in the number of $S$. mutans in the biofilms formed on the surfaces of the tested restorative materials after the application of the tested antibacterial mouthrinses on these materials.

\begin{tabular}{||c|c|c|c|c|c||}
\hline & $\begin{array}{c}\text { Stainless } \\
\text { steel }\end{array}$ & Amalgam & GIC & $\begin{array}{c}\text { Composite } \\
\text { resin }\end{array}$ & Enamel \\
\hline CHX 0.12\% & $1.14 \pm 0.58$ & $3.06 \pm 0.46$ & $3.58 \pm 0.84$ & $2.46 \pm 1.17$ & $2.55 \pm 1.05$ \\
\hline NaF 0.05\% & $0.29 \pm 0.36$ & $1.24 \pm 0.56$ & $1.53 \pm 0.78$ & $0.97 \pm 0.57$ & $1.07 \pm 0.71$ \\
\hline $\begin{array}{c}\text { NaF 0.05\%- } \\
\text { xylitol 25\% }\end{array}$ & $0.41 \pm 0.46$ & $1.71 \pm 0.58$ & $2.34 \pm 0.84$ & $1.19 \pm 0.65$ & $1.45 \pm 0.54$ \\
\hline
\end{tabular}

these values indicates that chlorhexidine gluconate $0.12 \%$ has the most effective antibacterial properties. On the other hand comparing sodium fluoride $0.05 \%$ with sodium fluoride $0.05 \%$ - xylitol $25 \%$ combination indicates that the addition of xylitol increases the antimicrobial effect of sodium fluoride, prominently for GIC and amalgam specimens.

Comparing the tested restorative materials regarding the sensitivity of $S$. mutans biofilms formed on their surfaces to antimicrobial treatments indicates that in the case of chlorhexidine gluconate and sodium fluoridexylitol combination, $S$. mutans biofilms formed on the surface of GIC specimens were significantly the most susceptible to the antibacterial effects of these two mouthrinses, while biofilms formed on the surface of stainless steel specimens were the least susceptible $(p<0.05)$. In the case of sodium fluoride $0.05 \%$ however, biofilms formed on GIC specimens were the most susceptible to the antimicrobial effects of sodium fluoride followed by the biofilms formed on amalgam specimens without statistical significant between these two restorative materials $(p>0.05)$. On the other hand, biofilms formed on the surface of stainless steel specimens showed the lowest level of susceptibility to sodium fluoride $(p<0.05)$.

\section{Discussion}

The in-vitro approach used in this study has the benefit of ensuring standardized test conditions, and therefore high reproducibility. On the other hand, the used in-vitro system integrated enamel, saliva, and S. mutans to mimic some in-vivo features. Nevertheless the batch culture technique used in this study has some disadvantages; as in contrast to the situation in the oral cavity, products of bacterial metabolism accumulate in batch cultures.

All of the test specimens were incubated with saliva for $2 \mathrm{hrs}$ prior to incubation with the bacterial suspension, as the salivary pellicle may influence microbial adhesion and metabolic activity significantly. This time of incubation was chosen based on previous studies that showed that the pellicle reaches its maximum thickness after $2 \mathrm{hrs}$ of saliva exposition $^{14}$.

Chlorhexidine gluconate has been demonstrated to be the most effective antibacterial agent in several studies like a study conducted by Poggio et al. ${ }^{12}$ and a study conducted by Auschill et al. ${ }^{18}$. This fact was also confirmed by the results of the present study, as chlorhexidine significantly reduced the count of $S$. mutans in biofilms formed by all of $S$. mutans clinical isolates on different dental restorative materials.

Very few data are available in literature about the specific effect of antibacterial mouthrinses on bacterial biofilms formed on different dental restorative materials ${ }^{3 \& 19}$. This study demonstrated that biofilms of S.mutans formed on various surfaces showed significant differences in the sensitivity to antimicrobial treatments. This result highlights the importance of choosing the relevant surface when testing the anti-biofilm effects of a given mouthrinse.

The results of the current study reported that biofilms formed on the surface of glassinomer cement specimens were the most susceptible to chlorhexidine, and on the other hand, biofilms formed on the surface of stainless steel specimens exhibited the lowest sensitivity to the antimicrobial treatment. A 
possible explanation for this phenomenon could be the differences in chlorhexidine adsorption rates onto different materials, as the surface of glass-inomer cement is relatively rougher and may adsorbs chlorhexidine to a larger extant compared with the smooth surface of stainless steel specimens, add to that the probable synergetic effect of chlorhexidine with the fluoride released from glass-inomer cement.

Another explanation for this phenomenon may be attributed to the Microbiology-related corrosion of stainless steel, which can be defined as the deterioration of the metal surface due to the direct or indirect activity of microorganisms ${ }^{20}$. Bacteria in the biofilm decrease the $\mathrm{pH}$ by generating acidic metabolites; subsequently the surface oxides of the dental alloys dissolve, leading to decline in the corrosion resistance of the metal ${ }^{21}$. However, the altered surfaces of dental alloys can accelerate the expression of bacterial virulence genes and biofilm formation as a result. In this regard, Zhang et al. proposed that corroded alloy surfaces may upregulate gene expression of the glucosyltransferases B, C, D, glucan-binding proteins B, fructosyltransferase, and lactate dehydrogenase in $S$. mutans ${ }^{5}$. Thus, the increased accumulation of extracellular matrix producing a thick biofilm could play a critical role in the protection of $S$. mutans from the antibacterial activity of chlorhexidine.

Fluoride on the other hand, is one of the most important agents for controlling dental caries. The main proved mechanism of action of fluoride in caries management is by increasing mineral uptake by enamel and decreasing demineralization. However, another reported mode of action is by affecting bacterial metabolism ${ }^{22}$. In this regard, our study is in agreement with the results of many previous studies that demonstrated the antibacterial and antibiofilm properties of fluoride salts like the study of karami et al. ${ }^{23}$, and the in-vivo study conducted by Sajadi et $a l .{ }^{24}$. The effects of fluoride on streptococci are attributed in part to the inhibition of enolase, which is one of the glycolytic system enzymes, as this inhibition reduces the intracellular level of phosphoenolpyruvate (PEP), leading to decrease in bacterial sugar uptake through PEP-dependent phosphotransferase system (PEP-PTS). Furthermore, fluoride can inhibit bacterial proton-translocating ATPase that is partly responsible for the proton fluxion out of the cells, resulting in acidification of the intracellular PH. The dissociation of unionized hydrofluoric acid into $\mathrm{H}^{+}$and $\mathrm{F}^{-}$in the cells also promotes intracellular acidification ${ }^{9}$. The results of these events together lead eventually to reduction in the bacterial metabolic activity.

As in the case of chlorhexidine, biofilms of S.mutans formed on various restorative surfaces showed significant differences in the sensitivity to the antibacterial properties of sodium fluoride, as biofilms formed on the surface of glass-inomer cement specimens were the most susceptible to sodium fluoride, followed by amalgam with no statistical significant between the two materials, while biofilms formed on the surface of stainless steel specimens exhibited the lowest sensitivity to this antimicrobial treatment. This result can be also explained by the same reasons mentioned in the case of chlorhexidine, relating to the different levels of antibacterial agent adsorption onto the surface of different dental materials, biocorrosion of the metal alloy in stainless steel leading to thicker more resistant biofilm, in addition to the probable additive effect of the external fluoride derived from the mouthwash to the fluoride that is naturally released from glass inomer cement specimens.

Considering the significant role of $S$. mutans in the development of dental caries, and because of the side effects of chlorhexidine, in addition to the limited antimicrobial efficacy of sodium fluoride compared with chlorhexidine as noticed in the current study, we tried to investigate the therapeutic effects of xylitol and sodium fluoride combination mouthwash on $S$. mutans biofilm in an attempt to meet the optimum criteria of an efficient mouthwash with sweet taste.

The results of the current study reported that sodium fluoride $0.05 \%$ - xylitol $25 \%$ combination mouthrinse significantly decreased the count of $S$. mutans in biofilms formed on the surfaces of all of the tested restorative materials confirming the effective antibacterial properties of this combination. These properties may be explained by the results of previous studies that investigated the intracellular glycolytic intermediates, and reported that xylitol inhibits the upper part of the glycolytic pathway, while fluoride inhibits 
the lower part of $\mathrm{it}^{9}$. Our results are in accordance with a study performed by Goncalves et $\mathrm{al}^{25}$, in which they reported a reduction of salivary $S$. mutans after using $0.05 \% \mathrm{NaF}$ solution containing xylitol. On the other hand, this result is in disagreement with the findings of Giertsen et al. ${ }^{26}$, in which, they concluded that using $0.025 \% \mathrm{NaF}+20 \%$ xylitol did not affect the levels of mutans streptococci in dental plaque and saliva, this disagreement may be attributed mainly to the different concentrations of fluoride and xylitol used.

Moreover, the result of this study also demonstrated once again that biofilms of S.mutans formed on various surfaces showed significant differences in sensitivity to sodium fluoride - xylitol combination mouthwash, as biofilms formed on the surface of glass inomer cement specimens were the most susceptible to this antibacterial treatment, while biofilms formed on the surfaces of stainless steel specimens exhibited the lowest level of sensitivity. Beside the different levels of mouthrinse adsorption between the tested materials, and biocorrosion of the stainless steel specimens, this result can be also attributed to the synergetic effect of xylitol and fluoride, taking into account the fluoride released from the glass inomer cement specimens as well.

Comparing the antibacterial effects of the three tested mouthrinses indicates that chlorhexidine gluconate $0.12 \%$ was the most effective antibacterial mouthrinse on $S$. mutans biofilms formed on all of the tested restorative materials. In this regard, many previous studies have also confirmed that chlorhexidine has the best anti-plaque properties, and that it is still considered the golden standard against which the efficacies of other antimicrobial agents are compared $^{7}$. This is in accordance with the findings of Nassar et $a .^{22}$ in which they concluded that the antibacterial properties of chlorhexidine are superior to those of sodium fluoride. However, the results of the current study disagreed with the results of a study conducted by Zajkani et $a .^{27}$ in which they reported no statistically significant differences between the antibacterial effects of chlorhexidine, and sodium fluoride-xylitol mouthrinses, this disagreement may be attributed to the different concentrations of chlorhexidine, fluoride and xylitol concentrations used.

On the other hand, comparing sodium fluoride $0.05 \%$ - xylitol $25 \%$ combination mouthrinse with sodium fluoride $0.05 \%$ alone have shown that the addition of xylitol $25 \%$ to sodium fluoride mouthrinse was associated with increased antibacterial effects, prominently on the biofilms formed on GIC and amalgam specimens. This may be explained by the possible synergistic effects of sodium fluoride and xylitol in inhibiting bacterial glycolytic pathways as mentioned earlier.

\section{Conclusion}

Within the limitation of the current study we concluded that:

- Chlorhexidine gluconate $0.12 \%$, sodium fluoride $0.05 \%$, and sodium fluoride $0.05 \%$ xylitol $25 \%$ combination exhibited statistically significant antibacterial effects on $S$. mutans biofilm.

- Chlorhexidine mouthrinse exhibited the highest antibacterial efficacy in reducing $S$. mutans count in the biofilm.

- The addition of xylitol $25 \%$ to sodium fluoride $0.05 \%$ mouthrinse increased the antibacterial effects of this mouthrinse.

- Most importantly; S. mutans biofilms formed on the surfaces of different restorative materials exhibited different sensitivity levels to the tested mouthrinses, as biofilms formed on GIC specimens showed the highest sensitivity, while biofilms formed on stainless steel specimens exhibited the lowest susceptibility to antimicrobial treatments.

\section{REFERENCES}

1- H. Fung, et al., "Early Childhood Caries: A Literature Review", Oral Hygiene \& Health (2013).

2- M. Øilo and V. Bakken, "Biofilm and dental biomaterials", Materials, 8 (6), 2887-2900 (2015).

3- E. Brambilla, et al., "Biofilm formation on composite resins for dental restorations: an in-situ study on the effect of chlorhexidine mouthrinses", The International Journal of Artificial Organs, 35 (10), $792-799$ (2012). 
4- L. V. Lassila, et al., "Adherence of Streptococcus mutans to fiber-reinforced filling composite and conventional restorative materials", The Open Dentistry Journal, 3, 227-232 (2009).

5- S. Zhang, et al., "Reciprocal interaction between dental alloy biocorrosion and Streptococcus mutans virulent gene expression", Journal of Materials Science: Materials in Medicine, 27 (4), 78 (2016).

6- D. Gupta, et al., "Comparative evaluation of Terminalia chebula extract mouthwash and chlorhexidine mouthwash on plaque and gingival inflammation-4-week randomised control trial", Oral Health \& Preventive Dentistry, 13 (1), 5-12 (2015).

7- P. Sajjan, et al., "Chlorhexidine as an antimicrobial agent in dentistry - A review", Oral Health and Dental Management, 15 (2), 93-100 (2016).

8- E. A. Martínez-Mier, "Fluoride: Its metabolism, toxicity, and role in dental health", Journal of Evidence-Based Complementary \& Alternative Medicine, 17 (1), 28-32 (2012).

9- P. Subramaniam and N. Nandan, "Effect of xylitol, sodium fluoride and triclosan containing mouth rinse on Streptococcus mutans", Contemporary Clinical Dentistry, 2 (4), 287-290 (2011).

10- P. A. Nayak, U. A. Nayak and V. Khandelwal, "The effect of xylitol on dental caries and oral flora", Clinical, Cosmetic and Investigational Dentistry, 6, 89-94 (2014).

11- E. Jalalian, G. Mofrad and S. Ahmadpour, "Adhesion of Streptococcus mutans to glass ionomer, BisCem cement and enamel: An in-vitro study", Journal of Dentistry (Tehran), 12 (9), 678-685 (2015).

12- C. Poggio, et al., "Adhesion of Streptococcus mutans to different restorative materials", The International Journal of Artificial Organs, 32 (9), 671677 (2009).

13- P. P. Pita, J. A. Rodrigues, C. OtaTsuzuki, T. F. Miato, E. G. Zenobio, G. Giro, L. C. Figueiredo, C. Gonçalves, S. A. Gehrke, A. Cassoni and J. A. Shibli, "Oral Streptococci biofilm formation on different implant surface topographies",
BioMed Research International, 2015, 159625 (2015).

14- S. Hahnel, et al., "Streptococcus mutans and Streptococcus sobrinus biofilm formation and metabolic activity on dental materials, Acta Odontologica Scandinavica, 70 (2), 114-121 (2012).

15- C. Nabert-Georgi, A. C. Rodloff, H. Jentsch, D. R. Reissmann, R. Schaumann and C. S. Stingu, "Influence of oral bacteria on adhesion of Streptococcus mutans and Streptococcus sanguinis to dental materials", Clinical and Experimental Dental Research, 4 (3), 7277 (2018).

16- L. Li, M. B. Finnegan, S. Özkan, Y. Kim, P. B. Lillehoj, C. M. Ho, R. Lux, R. Mito, Z. Loewy and W. Shi, "In- vitro study of biofilm formation and effectiveness of antimicrobial treatment on various dental material surfaces", Molecular Oral Microbiology, 25 (6), 384-390 (2010).

17- Sahra Kırmusaoğlu, "The Methods for Detection of Biofilm and Screening Antibiofilm Activity of Agents", In: Antimicrobials, Antibiotic Resistance, Antibiofilm Strategies and Activity Methods", IntechOpen (2019).

18- T. M. Auschill, et al., "Effect of two antimicrobial agents on early in-situ biofilm formation", Journal of Clinical Periodontology, 32 (2), 147-152 (2005).

19- R. Sousa, et al., "In-situ effects of restorative materials on dental biofilm and enamel demineralization", Journal of Dentistry, 37 (1), 44-51 (2009).

20- C. Lu, Y. Zheng and Q. Zhong, "Corrosion of dental alloys in artificial saliva with Streptococcus mutans", PLoS ONE, 12 (3), e0174440 (2017).

21- Y. Hao, et al., "Influence of dental prosthesis and restorative materials interface on oral biofilms", International Journal of Molecular Sciences, 19 (10), 3157 (2018).

22- H. M. Nassar and R. L. Gregory, "Biofilm sensitivity of seven Streptococcus mutans strains to different fluoride levels", Journal of Oral Microbiology, 9 (1), 1328265 (2017).

23- M. Karami, R. Mazaheri and M. Mesripour, "comparing the effectiveness of two fluoride mouthrinses on 
Streptococcus mutans", Journal of Mashhad Dental School, 35 (2), 115-122 (2011).

24- F. S. Sajadi, et al., "Effect of fluoride, chlorhexidine and fluoride-chlorhexidine mouthwashes on salivary Streptococcus mutans count and the prevalence of oral side effects", Journal of Dental Research, Dental Clinics, Dental Prospects, 9 (1), 49-52 (2015).

25- N. Goncalves, et al., "Effect of sodium fluoride mouth rinses containing xylitol and sorbitol on the number of Streptococcus mutans from human saliva", Revista Panamericana de Salud Publica, 9 (1), 30-34 (2001).

26- E. Giertsen, H. Emberland and A. A. Scheie, "Effects of mouth rinses with xylitol and fluoride on dental plaque and saliva", Caries Research, 33 (1), 23-31 (1999).

27- E. Zajkani, et al., "Comparison of the Effect Of 0.2\% Chlorhexidine and Xylitol Plus 920 Ppm Fluoride Mouthwashes on Count of Salivary Streptococcus Mutants, A Pilot Study", Journal of Dentistry, 19 (4), 301-304 (2018). 


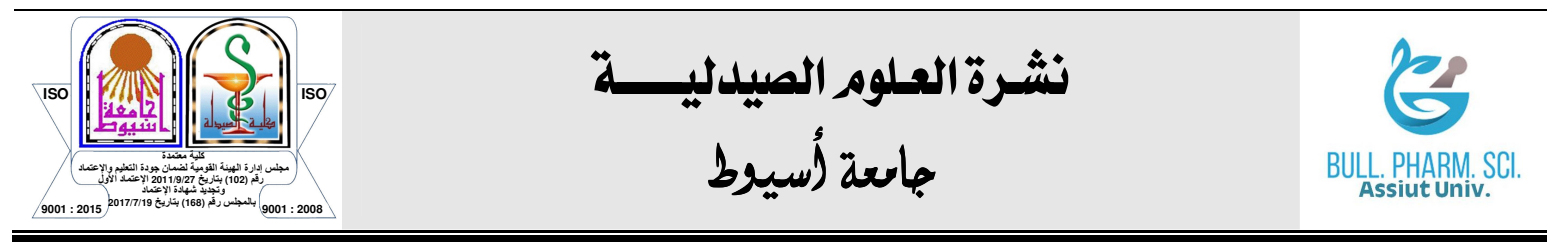

تأثير المواد الترميمية المختلفة على حساسية بيوفيلم العقديات الطافرة لتأثير

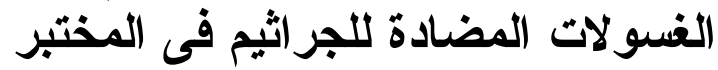

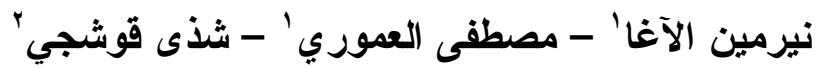

'قسم الكيمياء الحيوية والأحياء الدقيقة ، كلية الصيدلة ، جامعة دمشق ، دمشق ، سورية

'قسم طب أسنان الأطفال ، كلية طب الأسنان ، جامعة دمشق ، دمشق ، سورية الحيل

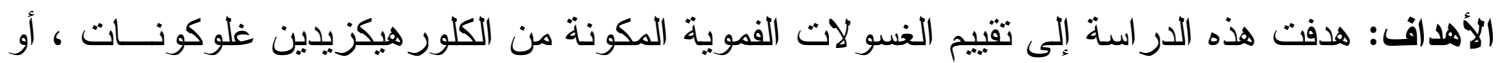

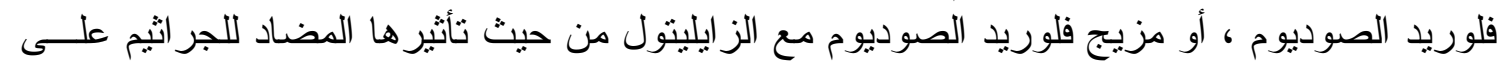

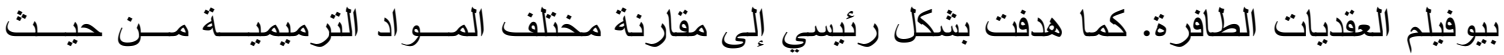

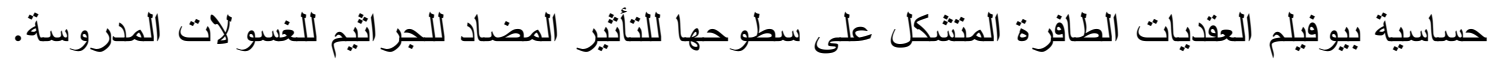

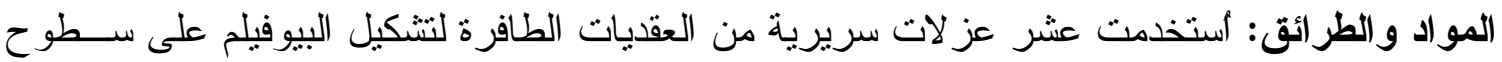

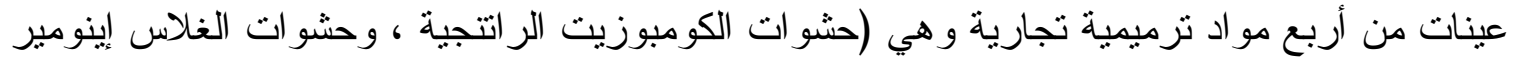

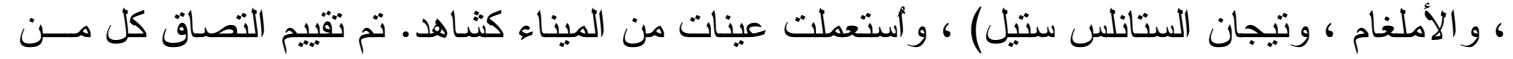

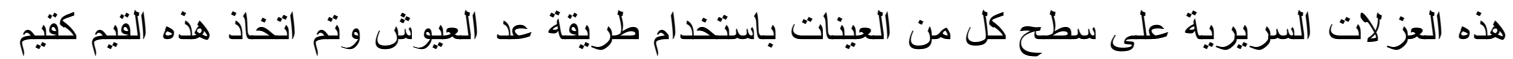

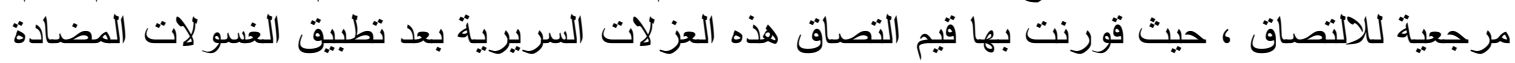

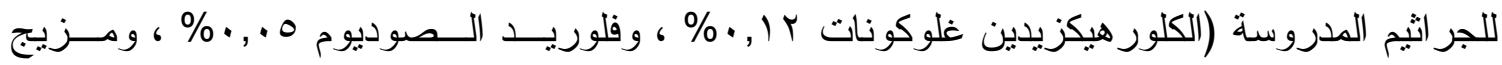

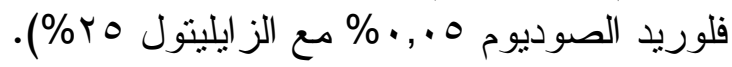

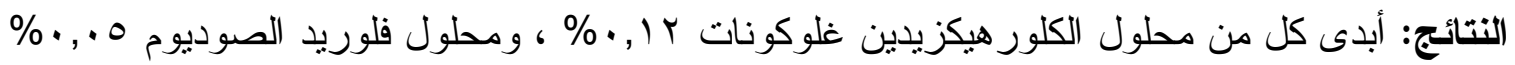

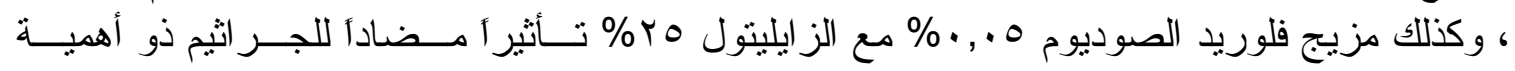

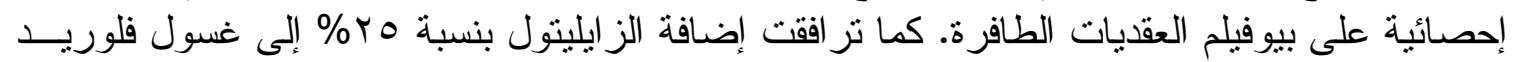

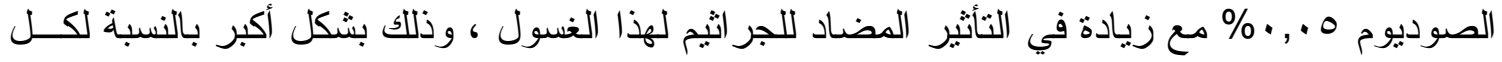

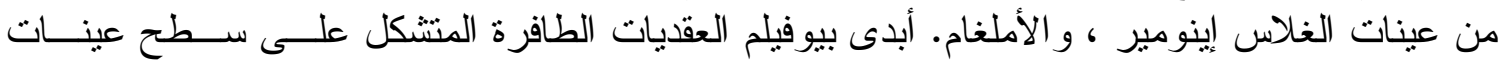

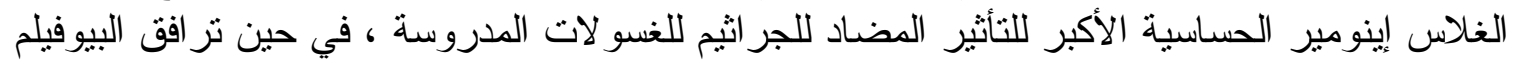
المتثكل على سطح عينات الستانلس ستيل مع الحساسية الأقل.

الخلاصة: أبدى بيوفيلم العقديات الطافرة المتشكل على سطوح مو اد ترميمية مختلفة حسساسية منباينــة

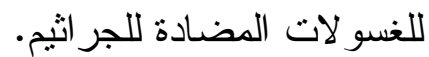

